\title{
Optimization of the Kinematic Parameter and Fuel Consumption for the Side-Shift Offset Rotavator Using L and J-Shape Soil Cutting Blades
}

\author{
Shekhar Kumar Sahu*, Kunj Bihari Tiwari, Prateek Shrivastava and Rohit Namdeo
}

Department of Farm Machinery and Power Engineering, College of Agricultural Engineering, Jabalpur - 482004, India

*Corresponding author

\section{A B S T R A C T}

\begin{tabular}{|c|c|}
\hline Keywords & $\begin{array}{l}\text { The cover cropping in orchards is an advantageous method of weeding which suppresses } \\
\text { the weed growth as well as adds additional income. The side-shift offset rotavator was }\end{array}$ \\
\hline $\begin{array}{l}\text { Side-shift offset } \\
\text { rotavator, Cover } \\
\text { cropping, } \lambda \text {-atio, } \\
\text { MMD, Intra-row } \\
\text { weeding. }\end{array}$ & $\begin{array}{l}\text { used to prepare a weed free seed bed in orchard field. Certain machine and soil parameter } \\
\text { which governs the quality of a seedbed were selected as independent factors, it included: } \\
\text { type of cutting blade; kinematic parameter and soil moisture content. While the soil } \\
\text { particle size, weeding efficiency and fuel consumption was considered as the dependent } \\
\text { parameters. In optimization process, it was observed that the L-shape blade gives } 86.84 \%\end{array}$ \\
\hline Arti & $\begin{array}{l}\text { finer soil particle, but consumes } 19.53 \% \text { higher fuel than the } \mathrm{J} \text {-shape blade at optimized } \\
\text { soil moisture content and lambda ratio of } 16.40 \% \text { and } 8.83 \text { respectively. The regression }\end{array}$ \\
\hline $\begin{array}{l}\text { Accepted: } \\
\text { 12 July } 2018 \\
\text { Available Online: } \\
10 \text { August } 2018\end{array}$ & $\begin{array}{l}\text { odel for mean mass diameter and fuel consumption has the coefficient of determination } \\
2^{2} \text { value) of } 0.8716 \text { and } 0.9037 \text { respectively at } 1 \% \text { level of significance. It was found that } \\
\text { ere was a significant effect of soil moisture content, type of soil cutting blade and } \\
\text { mbda ratio on the performance of side-shift offset rotavator. }\end{array}$ \\
\hline
\end{tabular}

\section{Introduction}

Cultivation of the cover crop in orchards, the soil, covered by the tree canopy needs weeding as well as proper pulverization for aeration. The available tillage implements are not much suitable to perform these operations under the tree due to the hindrance of branches. In order to perform tillage in this area, it is necessary that the implement width must be equal to the radius of the canopy. In this regard, the offset disc harrow and offset rotavator (without shifting mechanism) have been introduced. The offset disc harrow is efficient to cut the weed but unable to produce a good seedbed in a single pass. On the other hand, the offset rotavator is very efficient for weeding and pulverizing the soil. Nevertheless, the limitation of both the implement is that they are not convenient for intra-row weeding and ploughing. The reason behind it is that the gang of disc harrow or rotor assembly strikes with the stem of the tree. Because they follow a straight path during the operation and cannot shift centre ward as they are not featured with shifting mechanism. The side shift offset rotavatorused in the experimentwas equipped with $\mathrm{J}$-shape cutting blades. In ploughing perspective, its operation was found undesirable. The reason 
behind that it forms the ridge and valley type of soil profile during tilling which is not a desirable seed bed (Gill and Hendrick, 1976) as shown in Figure 1. The uniform depth of pulverized soil was found about $4-5 \mathrm{~cm}$ below from the top. Below this depth, the soil left untilled due to the curved shape of the blade. The intersection point of two consecutive blades of the same flange is the interesting point. Respectively, above and below this point tilled and untilled soil was formed as shown in Figure 1.

Considering the above-discussed issues, the $\mathrm{J}-$ shape blade was replaced with a commercially available L-shape blade and the operating parameters were optimized. Primarily, in this study, kinematic parameter and soil moisture content were focused for optimization which substantially influences the soil particle size, weeding efficiency and fuel consumption.

\section{Materials and Methods}

\section{Design of experimental layout}

Initially, the independent parameters were selected and theiroperating levels were determined on the basis of review and preliminary trials. Subsequently, the experimental layout was prepared using asymmetricfull factorial randomized design (Fig. 2). Total 32 treatments were obtained which were run on the field and mean mass diameter of soil, weeding efficiency and fuel were determined by following standard methods. The response surface methodology was applied for optimization of the shape of cutting blades, soil moisture and kinematic parameter.

\section{Independent parameters}

The independent parameters were selected from the soil, machine and operational parameters. The hypothesis of testing was assumed that there will be a significant difference in soil particle size, weeding efficiency and fuel consumption for different soil moisture content and kinematic parameters for both types of the soil cutting blades.

\section{Moisture content of the soil}

The soil moisture content affects the cohesion, adhesion as well as frictional forces. These forces determine the size of the soil particle when the soil is subjected to deformation. The failure or deformation of the soil due to shear occurs when the cutting blade of a rotary tiller interact with the soil during the tillage. Thus, the moisture affects the force requirement for soil pulverization and hence the fuel consumption. Therefore, the soil moisture content was considered as the important parameter which governs the performance of rotary tillers.

\section{Kinematic parameter $(\lambda-$ ratio $)$}

The $\lambda$-ratio is the dimensionless factor also known as a kinematic parameter, which affects the soil pulverization. Hendrick and Gill (1971c), defined this term as the ratio of the peripheral velocity of the rotor $\left(V_{\text {cir }}\right)$ to the forward velocity of the machine $\left(V_{f}\right)$. The variation in kinematic parameter depends upon the forward speed of the machine, rotational speed and radius of the rotor.

$$
\lambda=\frac{V_{\text {cir }}}{V_{f}}=\frac{R \omega}{V_{f}}=\frac{2 \pi R N}{60 V_{f}} \ldots 1
$$

Where, $\lambda=$ kinematic parameter (dimensionless); $V_{\text {cir }}=$ peripheral velocity of rotor, $(\mathrm{m} / \mathrm{s}) ; \mathrm{R}=$ radius of the rotor, $(\mathrm{m}) ; \omega=$ angular velocity of rotor, $(\mathrm{rad} / \mathrm{s})$. The above equation shows that the lambda ratio varies directly with the rotational speed of the rotor and inversely with the forward speed of the machine.In our experiments, the kinematic parameter was varied through changing the forward velocity of the machine by setting the 
gear ratio as given in Table 1. While the rotational speed of the rotor, number of blades on the flange and the depth of operation were kept constant. The graphical representation of the soil slice cut at different lambda ratio of $8.86,7.01,5.60$ and 4.80 made different bite length at a constant depth of $0.12 \mathrm{~m}$ are given in Figure 3.

\section{Rotational speed of the rotor}

The kinematic parameter is directly related to the rotational speed of the rotor as given in the equation 1. In order to obtain the various levels of kinematic parameters, the forward speed of travel was varied while the speed of the rotor was kept constant.

\section{Bite length}

The bite length or tilling pitch is defined as the length of soil cut on a horizontal plane by the two consecutive blade of the rotor mounted on the same direction of the same flange (Hendrick and Gill, 1971a). It is denoted by $\mathrm{L}_{\mathrm{b}}$, and given by the equation given below-

$$
\mathrm{L}_{\mathrm{b}}=\frac{\mathrm{V}_{\mathrm{f}} \times 60}{\mathrm{~N} \times \mathrm{Z}} \quad \ldots 2
$$

Where, $V_{\mathrm{f}}=$ Forward velocity of the machine, $(\mathrm{m} / \mathrm{s}) ; \mathrm{N}=$ Rotational speed of the rotor, (rpm), measured by anon-contacting type tachometer, andZ = Number of blades mounted on one flange in the same direction.Bite lengthwas variedby varying the forward speed. Thus, the volume of soil mass cut and thrown by the blade gets reducedwhich causes the fuel consumption also reduces.

\section{Type of soil cutting blade}

Two types of cutting blades having $\mathrm{J}$ and $\mathrm{L}-$ shape were used as schematically shown in Figure 4. The vertical and horizontal part of the cutting blade is known as leg and span of the blade. The L-shape blades are the most common and commercially available blade.
The reason behind using the L-shape blade is that it does not allow to form unploughed soilprofile. Because its fillet radius between lag and span is very small while large inJ-shape blade. Although, the operating depth and width were identical with the existing blade $\mathbf{J}-$ shape blade.

\section{Results and Discussion}

\section{Soil properties}

The determined values of soil properties like moisture content, bulk density, cohesion, and adhesion force and cone index are given in Table 2. It was found that the bulk density of the soil does not have a direct relationship with the soil moisture. But by increasing the soil moisture from 10 to $16.40 \%$ the (within the adhesion phase of the soil), the cohesion and adhesion force increases. It was also observed that the penetration resistance also increases with the bulk density of the soil.

The shear failure envelopes of the soil-soil and soil-metal at different soil moisture are shown in the Figure 5 and 6 respectively. The figure depicted that the normal and shear stress has a positive correlation and follows the linear regression very well. Marenya, (2010) also studied about this relationship and reported that it fits well with a linear regression model. The cohesion and adhesion frictional forces were increased with the bulk density of the soil. The cone index was also found to be increased with the bulk density. A similar result was reported by Carlos et al., (2001).

Effect of the cutting blade of the rotor, kinematic parameter and soil moisture content on mean mass diameter

ANOVA Table 3 and Figure $7 \mathrm{a}$ to $7 \mathrm{~d}$ reveals that the MMD of the soil differs significantly at $1 \%$ probability level with the type of cutting blade, soil moisture content, and the lambda 
ratio. The MMD was found to be decreased from 0.77 to $0.57 \mathrm{~mm}$ when the rotor was equipped with $\mathrm{J}$ and $\mathrm{L}$-shape blade respectively at constant values (average value of all the four levels) of soil moisture and $\lambda-$ ratio of $13.20 \%$ and 6.83 respectively. It could be due to the difference in macro-shape and edge-shape of the blades.

The term macro-shape and edge-shape refers to the blade's gross surface and peripheral shapes respectively. This corresponds to design of the blade surface over which movement of soil occurs during the pulverization. The L-shape blade has larger macro-shape and edge-shape as shown in Figure 4. It was observed that the MMD was increased proportionally with the soil moisture. It might be due to the increase in cohesive force due to adding the moisture.

It is shown in Figure 7c that the MMD got finer from 1.11 to $0.42 \mathrm{~mm}$ with an increase in $\lambda$-ratio from 4.80 to 8.86 at constant soil moisture level of $13.20 \%$. This could be due to a decreasein bite length or an increase in soil cutting frequency when forward speed was reduced. The reduced forward speed cause the cycloid of cutting blade comes closer consequently the rotor blade cuts the soil of smaller bite length and thus, the soil particles were finer.A similar pattern has been reported by Destain and Houmy (1990) who studied the effect of kinematic parameter of the rotary tiller on soil structure.

The interaction effect of different $\lambda$-ratio and soil moisture $(\mathrm{M} \times \mathrm{L})$ was found significant as shown in the Figure 7d. Initially, the lowest value of MMD was measured as $0.26 \mathrm{~mm}$, because of the combined effect of the highest level of $\lambda$-ratio8.86 and lowest value of soil moisture $10 \%$ respectively. In this combination, the MMD increases and attains the maximum value of $2.07 \mathrm{~mm}$ at lambda ratio of 4.80 and $16.40 \%$ soil moisture content respectively.
Effect of thecutting blade of the rotor, kinematic parameter and soil moisture content on weeding efficiency

Among all the independent parameters (i.e. type of blade, soil moisture content, and $\lambda-$ ratio), no parameters werefound which significantly influence the weeding efficiency at $1 \%$ level of significanceas given in ANOVA Table 4.This could be due to the reason that the blade of either type when once enters into the soil, it cuts the weed completely for all levels of the kinematic parameter and soil moisture. Therefore, the difference in weeding efficiency was negligible.

Effect of the cutting blade of the rotor, kinematic parameter and soil moisture content on fuel consumption

The ANOVA Table 5 and Figure 8 reflects that the fuel consumption significantly affected by the type of cutting blade of the rotor, kinematic parameter and soil moisture content at $1 \%$ probability level. The values of "Prob. > F" less than 0.01 indicate model terms are significant. In this case, B, M, L and $\mathrm{BM}$ were significant model terms. It was found that the amount of the fuel consumed by the $\mathrm{J}$-shape blade was lower $3.00 \mathrm{l} / \mathrm{h}$ whereas, it was found to be little higher $3.20 \mathrm{l} / \mathrm{h}$ for $\mathrm{L}-$ shape blade for a constant value of soil moisture and lambda ratio of 6.83and $13.20 \%$ respectively. This might be due to more energy required by the $\mathrm{L}$-shape blade for throwing the greater mass of soil due to its larger length of leg and span (referring to Fig. 4). The fuel consumption was found to bedecreased from 3.23 to $2.80 \mathrm{l} / \mathrm{h}$ with an increase in soil moisture from 10.00 to $16.40 \%$ at the constant value of lambda ratio (6.83) for any blade. This could be due to the lower force required for cutting the soft soil as compared to hard or cemented soil. The fuel consumption was found to be higher at 3.19 $\mathrm{l} / \mathrm{h}$ at a lower value of the lambda ratio (4.80). 
While it was found to be lesser $2.85 \mathrm{l} / \mathrm{h}$ at higher lambda ratio (8.86). This could be due to the cutting of small bite length at higher lambda ratio which causes the blade has to throw the less volume of soil per blade. The ANOVA Table 5 and Figure 8 reveals that there is a significant effect of the interaction of soil moisture content and $\lambda$-ratio on fuel consumption. The black and red contour (Fig. 8d) refers to $\mathrm{J}$-shape and $\mathrm{L}$-shape blade respectively. It is shown in the figure that the fuel consumption was reduced from 3.23 to $2.80 \mathrm{l} / \mathrm{h}$ and 3.27 to $3.14 \mathrm{l} / \mathrm{h}$ for $\mathrm{J}$-shape and L-shape blade respectively when the soil moisture was reduced from 16.40to $10.00 \%$ at a constant value of lambda ratio (6.83).

Table.1 Operating levels of ratio at the different forward speed of the tractor (constant rotational speed of the rotor)

\begin{tabular}{|c|c|c|c|c|c|c|}
\hline \multirow{3}{*}{$\begin{array}{c}\text { Gear } \\
\text { position }\end{array}$} & \multirow{2}{*}{\multicolumn{2}{|c|}{$\begin{array}{c}\text { Forward speed } \\
\text { of the tractor, } \\
V_{\mathrm{f}}\end{array}$}} & \multicolumn{2}{|c|}{ Speed of the rotor } & \multirow{3}{*}{$\begin{array}{l}\text { Kinematic } \\
\text { para- } \\
\text { meter }\left(\lambda=\frac{v_{\text {cir }}}{v_{f}}\right)\end{array}$} & \multirow{3}{*}{$\begin{array}{l}\text { Bite length, } \\
\underbrace{}_{L_{b}}=\frac{\underbrace{}_{\mathrm{f}} \times 60}{N \times Z}\end{array}$} \\
\hline & & & \multirow{2}{*}{$\begin{array}{l}\text { Peripheral speed } \\
\qquad\left(V_{\text {cir }}\right)_{3} \mathrm{~m} / \mathrm{s}\end{array}$} & \multirow[t]{2}{*}{$\begin{array}{l}\text { Rotational } \\
\text { speed, rpm }\end{array}$} & & \\
\hline & $\mathrm{m} / \mathrm{s}$ & $\mathrm{Km} / \mathrm{h}$ & & & & \\
\hline $3^{\text {rd }}$ low & 0.53 & 1.90 & 4.70 & 280 & 8.86 & 0.038 \\
\hline $4^{\text {th }}$ low & 0.67 & 2.41 & 4.70 & 280 & 7.01 & 0.048 \\
\hline $1^{\text {st }}$ high & 0.84 & 3.02 & 4.70 & 280 & 5.60 & 0.060 \\
\hline $5^{\text {th }}$ low & 0.98 & 3.53 & 4.70 & 280 & 4.80 & 0.070 \\
\hline
\end{tabular}

Table.2 Bulk density, cone index, cohesion and adhesion forceat different moisture content

\begin{tabular}{|c|c|c|c|c|c|c|}
\hline \multirow{2}{*}{$\begin{array}{c}\text { Soil } \\
\text { moisture } \\
\text { content, }(\%)\end{array}$} & \multirow{2}{*}{$\begin{array}{c}\text { Bulk } \\
\text { density, } \\
\text { Kg/m } \text { m }^{3}\end{array}$} & \multirow[t]{2}{*}{$\begin{array}{c}\text { Cone index, } \\
\mathrm{KN} / \mathrm{m}^{2}\end{array}$} & \multicolumn{2}{|c|}{ Friction force, $\mathrm{N} / \mathrm{m}^{2}$} & \multicolumn{2}{|c|}{$\begin{array}{c}\text { Friction angle, } \\
\text { degree }\end{array}$} \\
\hline & & & Cohesion & Adhesion & Internal & External \\
\hline 10.00 & 1680 & 780 & 10202 & 8986 & $33.42^{\circ}$ & $31.63^{\circ}$ \\
\hline 12.40 & 1790 & 1070 & 9675 & 7622 & $30.49^{\circ}$ & $28.23^{\circ}$ \\
\hline 14.95 & 1730 & 920 & 12233 & 7740 & $24.37^{\circ}$ & $21.65^{\circ}$ \\
\hline 16.40 & 1690 & 820 & 9427 & 5719 & $31.50^{\circ}$ & $21.45^{\circ}$ \\
\hline
\end{tabular}

Table.3 Analysis of Variance for mean mass diameter

\begin{tabular}{|c|c|c|c|c|c|}
\hline $\begin{array}{c}\text { Source of } \\
\text { variation }\end{array}$ & $\begin{array}{c}\text { Sum of } \\
\text { square }\end{array}$ & DOF & $\begin{array}{c}\text { Mean } \\
\text { square }\end{array}$ & $\mathbf{F}_{\text {calculated }}$ & $\begin{array}{c}\text { P-value, } \\
\text { Prob>F }\end{array}$ \\
\hline Model & 6.370 & 7 & 0.910 & 23.28 & $<0.0001^{*}$ \\
\hline $\mathbf{B}$ & 0.290 & 1 & 0.290 & 7.50 & $0.0114 \mathrm{~ns}$ \\
\hline $\mathbf{M}$ & 3.560 & 1 & 3.560 & 91.11 & $<0.0001^{*}$ \\
\hline $\mathbf{L}$ & 1.190 & 1 & 1.190 & 30.56 & $<0.0001^{*}$ \\
\hline $\mathbf{B \times M}$ & 0.075 & 1 & 0.075 & 1.91 & $0.1794 \mathrm{~ns}$ \\
\hline $\mathbf{B} \times \mathbf{L}$ & 0.140 & 1 & 0.140 & 3.67 & $0.0676 \mathrm{~ns}$ \\
\hline $\mathbf{B} \times \mathbf{M} \times \mathbf{L}$ & 0.310 & 1 & 0.310 & 8.00 & $0.0093^{*}$ \\
\hline Residual & 0.023 & 1 & 0.023 & 0.58 & $0.4548 \mathrm{~ns}$ \\
\hline Lack of fit & 0.940 & 24 & 0.039 & & \\
\hline Pure error & 0.940 & 23 & 0.041 & & \\
\hline Total & 0.000 & 1 & 0.000 & & \\
\hline
\end{tabular}

* Denotes highly significant, i.e. at the $1 \%$ level of significance, ns: not significant. 
Table.4 Analysis of Variance for weeding efficiency

\begin{tabular}{|c|c|c|c|c|c|}
\hline Source of variation & Sum of square & DOF & Mean square & $\mathbf{F}_{\text {calculated }}$ & P-value, Prob>F \\
\hline Model & 661.76 & 7 & 94.54 & 1.46 & $0.2287 \mathrm{~ns}$ \\
\hline $\mathbf{B}$ & 0.87 & 1 & 0.87 & 0.013 & $0.9087 \mathrm{~ns}$ \\
\hline $\mathbf{M}$ & 6.44 & 1 & 6.44 & 0.099 & $0.7552 \mathrm{~ns}$ \\
\hline $\mathbf{L}$ & 303.64 & 1 & 303.64 & 4.69 & $0.0405 \mathrm{~ns}$ \\
\hline $\mathbf{B} \times \mathbf{M}$ & 27.78 & 1 & 27.78 & 0.43 & $0.5188 \mathrm{~ns}$ \\
\hline $\mathbf{M} \times \mathbf{L}$ & 19.57 & 1 & 19.57 & 0.30 & $0.5876 \mathrm{~ns}$ \\
\hline $\mathbf{B} \times \mathbf{M} \times \mathbf{L}$ & 259.91 & 1 & 259.91 & 4.01 & $0.0566 \mathrm{~ns}$ \\
\hline Residual & 99.16 & 1 & 99.16 & 1.53 & $0.2279 \mathrm{~ns}$ \\
\hline Lack of fit & 1554.49 & 24 & 64.77 & & \\
\hline Pure error & 1554.49 & 23 & 67.59 & & \\
\hline Total & 0.000 & 1 & 0.000 & & \\
\hline
\end{tabular}

* Denotes highly significant, i.e. at the $1 \%$ level of significance, ns: not significant.

Table.5 ANOVA table for fuel consumption

\begin{tabular}{|c|c|c|c|c|c|}
\hline Source of variation & Sum of square & DOF & Mean square & $\mathbf{F}_{\text {calculated }}$ & P-value, Prob>F \\
\hline Model & 1.25 & 7 & 0.18 & 32.16 & $<0.0001^{*}$ \\
\hline B & 0.27 & 1 & 0.27 & 48.34 & $<0.0001^{*}$ \\
\hline M & 0.36 & 1 & 0.36 & 65.53 & $<0.0001^{*}$ \\
\hline L & 0.46 & 1 & 0.46 & 82.91 & $<0.0001^{*}$ \\
\hline $\mathrm{B} \times \mathrm{M}$ & 0.11 & 1 & 0.11 & 19.71 & $0.0002^{*}$ \\
\hline $\mathrm{B} \times \mathrm{L}$ & $3.211 \mathrm{E}-003$ & 1 & $3.211 \mathrm{E}-003$ & 0.58 & $0.4548 \mathrm{~ns}$ \\
\hline $\mathrm{M} \times \mathrm{L}$ & 0.011 & 1 & 0.011 & 2.00 & $0.1704 \mathrm{~ns}$ \\
\hline $\mathrm{B} \times \mathrm{M} \times \mathrm{L}$ & 0.022 & 1 & 0.022 & 3.90 & $0.0597 \mathrm{~ns}$ \\
\hline Residual & 0.13 & 24 & $5.562 \mathrm{E}-003$ & & \\
\hline Lack of fit & 0.13 & 23 & $5.804 \mathrm{E}-003$ & & \\
\hline Pure error & 0.000 & 1 & 0.000 & & \\
\hline Total & 1.39 & 31 & & & \\
\hline
\end{tabular}

* Denotes highly significant, i.e. at the $1 \%$ level of significance, ns: not significant.

Table.6 Numerical optimization of the soil moisture and kinematic parameter for both blades

\begin{tabular}{|c|c|c|c|c|c|c|c|}
\hline \multirow[t]{2}{*}{ Name of variable } & \multirow{2}{*}{$\begin{array}{c}\text { Lower } \\
\text { limit }\end{array}$} & \multirow{2}{*}{$\begin{array}{l}\text { Upper } \\
\text { limit }\end{array}$} & \multirow[t]{2}{*}{ Weight } & \multicolumn{2}{|c|}{ Criteria } & \multirow{2}{*}{\multicolumn{2}{|c|}{$\begin{array}{l}\text { Predicted } \\
\text { value }\end{array}$}} \\
\hline & & & & Target & Importance & & \\
\hline \multicolumn{8}{|l|}{ Independent } \\
\hline Blade type & $\mathbf{J}$ & $\mathrm{L}$ & 1 & Range & 3 & $\mathbf{J}$ & $\mathrm{L}$ \\
\hline Moisture content, $\%$ & 10.00 & 16.40 & 1 & Range & 3 & 16.40 & 12.83 \\
\hline Lambda ratio & 4.80 & 8.90 & 1 & maximize & 3 & 8.83 & 8.86 \\
\hline \multicolumn{8}{|l|}{ Response } \\
\hline Mean mass dia., mm & 0.23 & 2.10 & 1 & Minimize & 3 & 0.71 & 0.38 \\
\hline Weeding efficiency, \% & 75.00 & 100.00 & 1 & Target & 4 & 99.00 & 99.00 \\
\hline Fuel consumption, $1 / \mathrm{h}$ & 2.50 & 3.50 & 1 & Minimize & 4 & 2.56 & 3.06 \\
\hline
\end{tabular}


Table.7 Reduced response model and statistical data obtained from the ANOVA

\begin{tabular}{|l|l|c|c|c|c|c|}
\hline Response & $\begin{array}{c}\text { Reduced model in terms of actual } \\
\text { factor }\end{array}$ & $\mathbf{R}^{\mathbf{2}}$ & $\begin{array}{c}\text { Adjus } \\
\text { ted } \mathbf{R}^{\mathbf{2}}\end{array}$ & $\begin{array}{c}\text { Model } \boldsymbol{p} \text { - } \\
\text { value }\end{array}$ & $\begin{array}{c}\text { Std. } \\
\text { dev. }\end{array}$ & $\begin{array}{c}\text { Adequate } \\
\text { precision }\end{array}$ \\
\hline For J-shape blade & & & & & \\
\hline MMD & $-3.1+0.38 \times \mathrm{MC}+0.27 \times \lambda-0.03 \times \mathrm{MC} \times \boldsymbol{\lambda}$ & 0.8716 & 0.8342 & $<0.0001$ & 0.20 & 16.94 \\
\hline $\boldsymbol{\eta}_{\mathbf{w}}$ & $49.44+2.16 \times \mathrm{MC}+6.32 \times \lambda-0.3 \times \mathrm{MC} \times \boldsymbol{\lambda}$ & 0.2986 & 0.0940 & 0.2287 & 8.05 & 5.44 \\
\hline FC & $3.41+0.01 \times \mathrm{MC}+0.07 \times \lambda-0.01 \times \mathrm{MC} \times \boldsymbol{\lambda}$ & 0.9037 & 0.8755 & $<0.0001$ & 0.08 & 23.31 \\
\hline For L-shape blade & & & & & \\
\hline MMD & $-2.11+0.25 \times \mathrm{MC}+0.17 \times \lambda-0.02 \times \mathrm{MC} \times \boldsymbol{\lambda}$ & 0.8716 & 0.8342 & $<0.0001$ & 0.20 & 16.94 \\
\hline $\boldsymbol{\eta}_{\mathbf{w}}$ & $-17.95+7.77 \times \mathrm{MC}+17.6 \times \lambda-1.2 \times \mathrm{MC} \times \boldsymbol{\lambda}$ & 0.2986 & 0.0940 & 0.2287 & 8.05 & 5.45 \\
\hline FC & $4.13-0.03 \times \mathrm{MC}-0.1 \times \lambda+0.002 \times \mathrm{MC} \times \boldsymbol{\lambda}$ & 0.9037 & 0.8755 & $<0.0001$ & 0.08 & 23.31 \\
\hline
\end{tabular}

Fig.2 Layout of the experimental field

110 meter

\begin{tabular}{|c|c|c|c|c|c|c|c|c|c|c|}
\hline $\mathrm{B}_{2} \mathrm{M}_{3} \mathrm{~L}_{4}$ & $\mathrm{~B}_{1} \mathrm{M}_{3} \lambda_{3}$ & $\mathrm{~B}_{1} \mathrm{M}_{1} \lambda_{3}$ & $\mathrm{~B}_{1} \mathrm{M}_{4} \lambda_{1}$ & $\mathrm{~B}_{1} \mathrm{M}_{1} \lambda_{2}$ & $\mathrm{~B}_{2} \mathrm{M}_{4} \lambda_{3}$ & $\mathrm{~B}_{2} \mathrm{M}_{1} \lambda_{3}$ & $\mathrm{~B}_{2} \mathrm{M}_{4} \lambda_{1}$ & $\mathrm{~B}_{2} \mathrm{M}_{4} \lambda_{4}$ & $\mathrm{~B}_{1} \mathrm{M}_{4} \lambda_{2}$ & $\mathrm{~B}_{2} \mathrm{M}_{2} \lambda_{3}$ \\
\hline $\mathrm{B}_{2} \mathrm{M}_{3} \lambda_{3}$ & $\mathrm{~B}_{1} \mathrm{M}_{2} \lambda_{3}$ & $\mathrm{~B}_{1} \mathrm{M}_{3} \lambda_{4}$ & $\mathrm{~B}_{1} \mathrm{M}_{3} \lambda_{2}$ & $\mathrm{~B}_{1} \mathrm{M}_{2} \lambda_{4}$ & $\mathrm{~B}_{1} \mathrm{M}_{1} \lambda_{1}$ & $\mathrm{~B}_{1} \mathrm{M}_{4} \lambda_{4}$ & $\mathrm{~B}_{2} \mathrm{M}_{2} \lambda_{4}$ & $\mathrm{~B}_{2} \mathrm{M}_{3} \lambda_{2}$ & $\mathrm{~B}_{2} \mathrm{M}_{2} \lambda_{2}$ & $\mathrm{~B}_{2} \mathrm{M}_{3} \lambda_{1}$ \\
\hline & $\mathrm{B}_{2} \mathrm{M}_{1} \lambda_{2}$ & $\mathrm{~B}_{2} \mathrm{M}_{2} \lambda_{1}$ & $\mathrm{~B}_{1} \mathrm{M}_{2} \lambda_{1}$ & & $\mathrm{~B}_{1} \mathrm{M}_{2} \lambda_{2}$ & & & $\mathrm{~B}_{1} \mathrm{M}_{3} \lambda_{1}$ & & \\
\hline
\end{tabular}

Fig.3 Shapes of the soil slice cut at different kinematic parameter $(\lambda$-ratio)

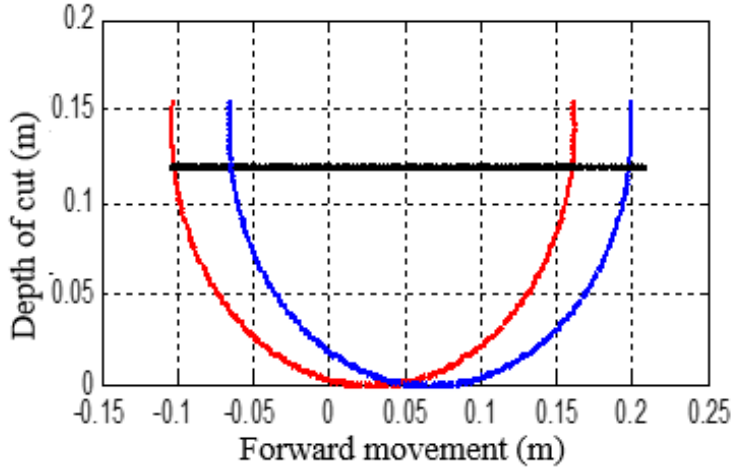

(a) $\lambda_{1}=8.86, \mathrm{~L}_{\mathrm{b} 1}=0.038 \mathrm{~m}$

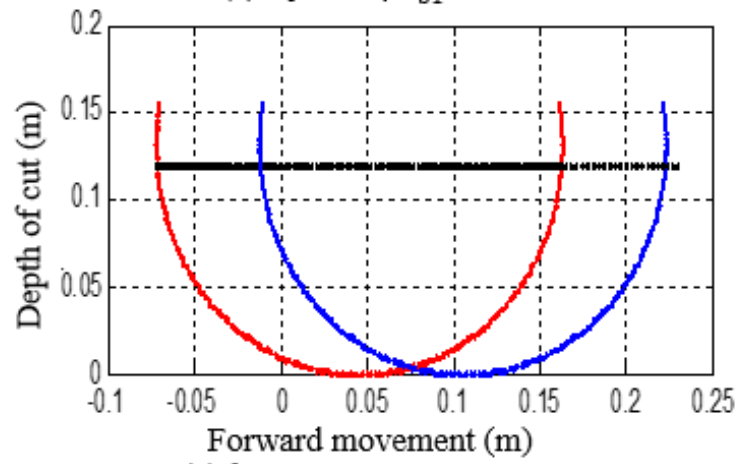

(c) $\lambda_{3}=5.60, \mathrm{~L}_{\mathrm{b} 1}=0.060 \mathrm{~m}$

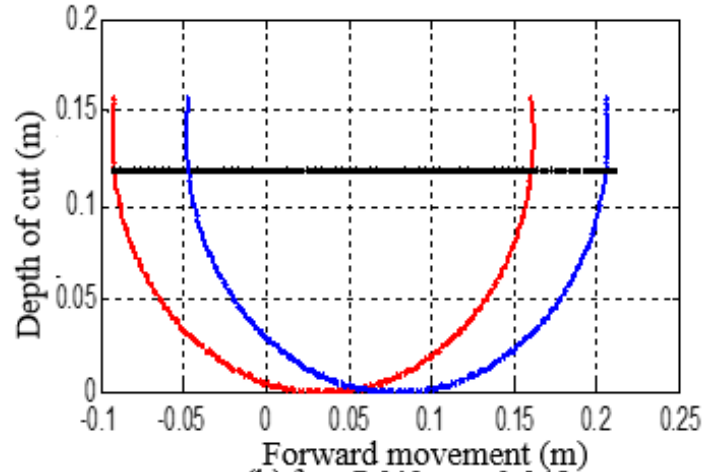

(b) $\lambda_{2}=7.01 \mathrm{~L}_{\mathrm{b} 1}=0.048 \mathrm{~m}$

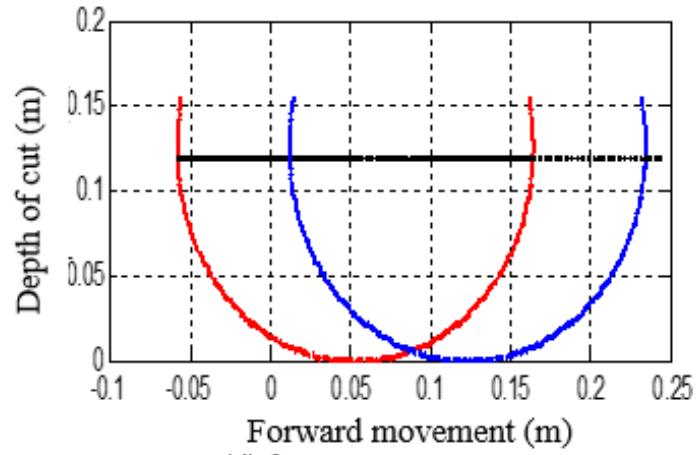

(d) $\lambda_{4}=4.80, \mathrm{~L}_{\mathrm{b} 1}=0.070 \mathrm{~m}$ 
Fig.1 Unploughed soil (ridge-valley) formed by using J-shape blade
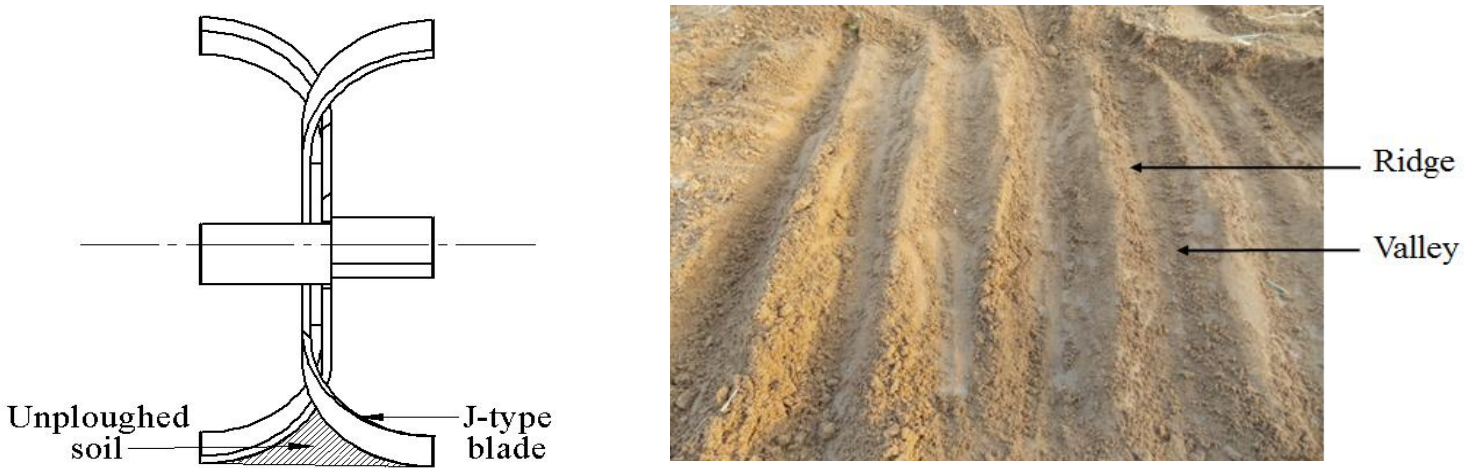

Fig.4 Types of soil cutting blade used in side-shift offset rotavator

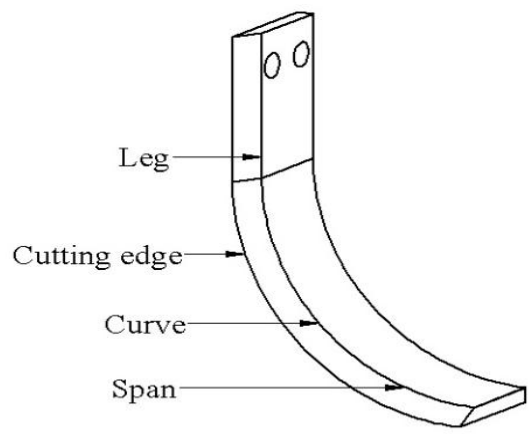

(a) J-Shape cutting blade

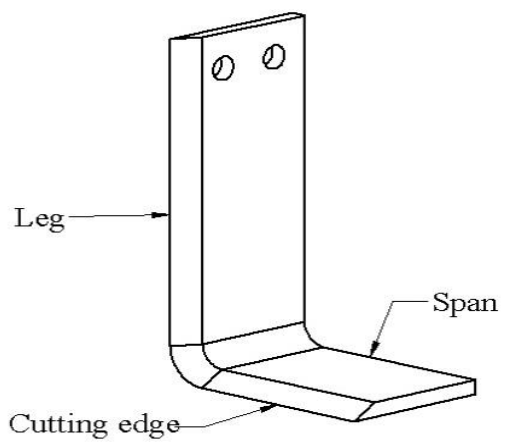

(b) L- Shape cutting blade

Fig.5 shear failure envelopes for the soil-soil at different moisture content

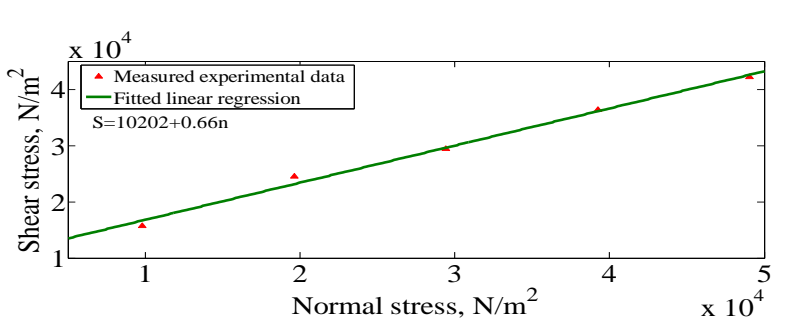

(a) Shear failure at $10.00 \%$ soil mc

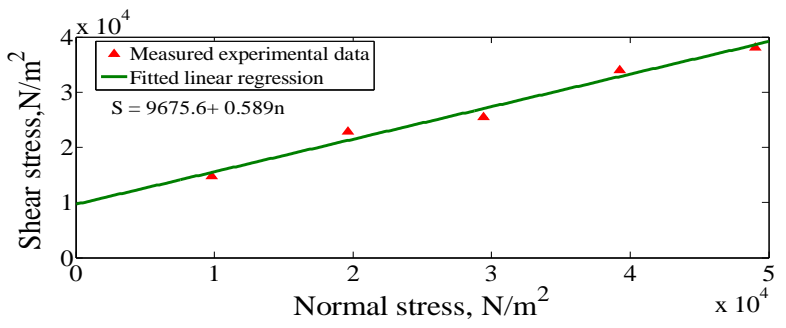

(b)Shear failure at $12.40 \%$ soil mc

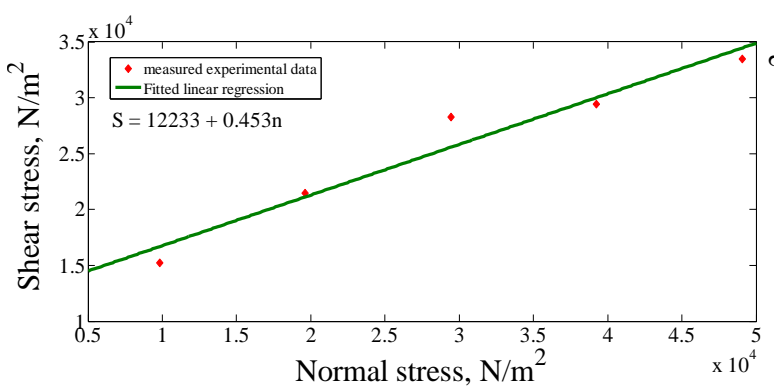

(c) Shear failure at $14.95 \%$ soil mc

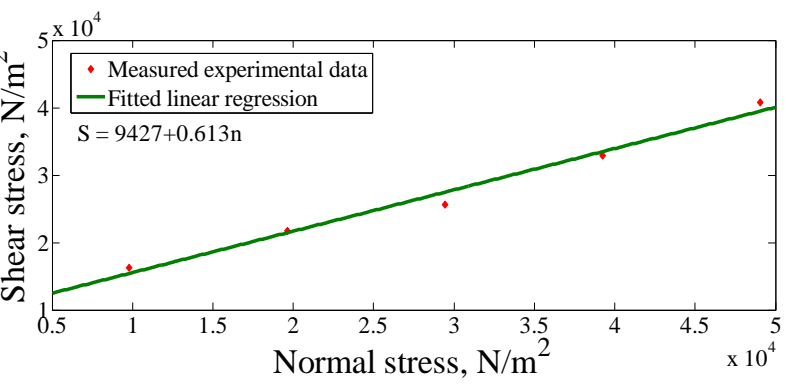

(d) Shear failure at $16.40 \%$ soil $\mathrm{mc}$ 
Fig.6 Shear failure envelopes for the soil-metal at different moisture content

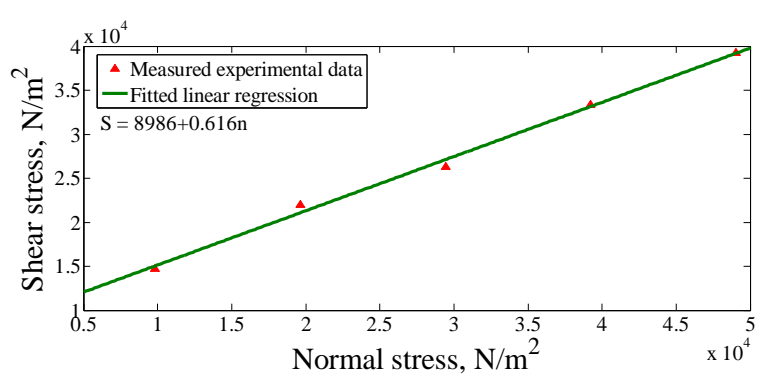

(a) Shear failure at $10.00 \%$ soil $\mathrm{mc}$

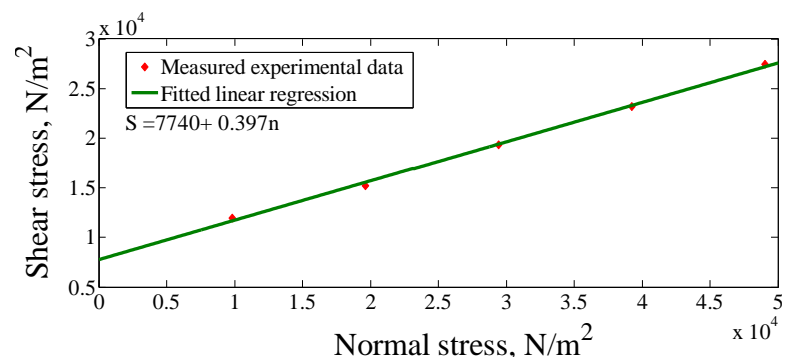

(c) Shear failure at $14.95 \%$ soil mc

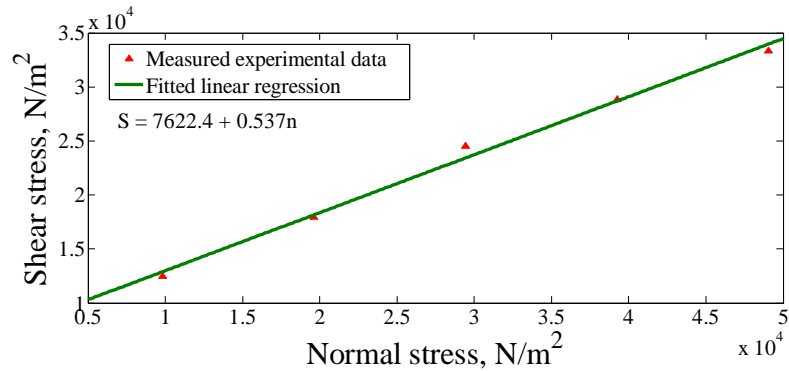

(b) Shear failure at $12.40 \%$ soil mc

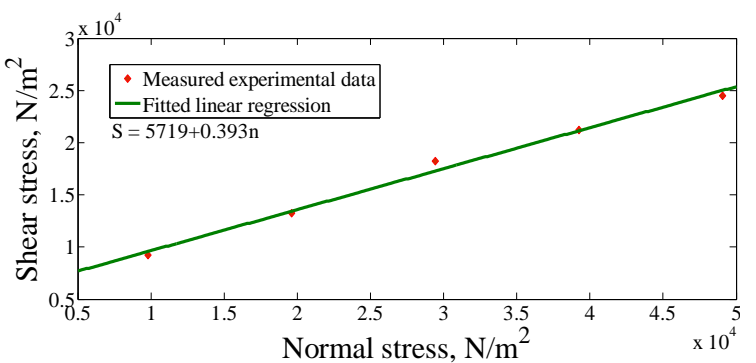

(d) Shear failure at $16.40 \%$ soil mc

Fig.7 Effect of the cutting blade on (a), soil moisture content (b), the kinematic parameter (c), and interaction effect (d) Mean Mass Diameter

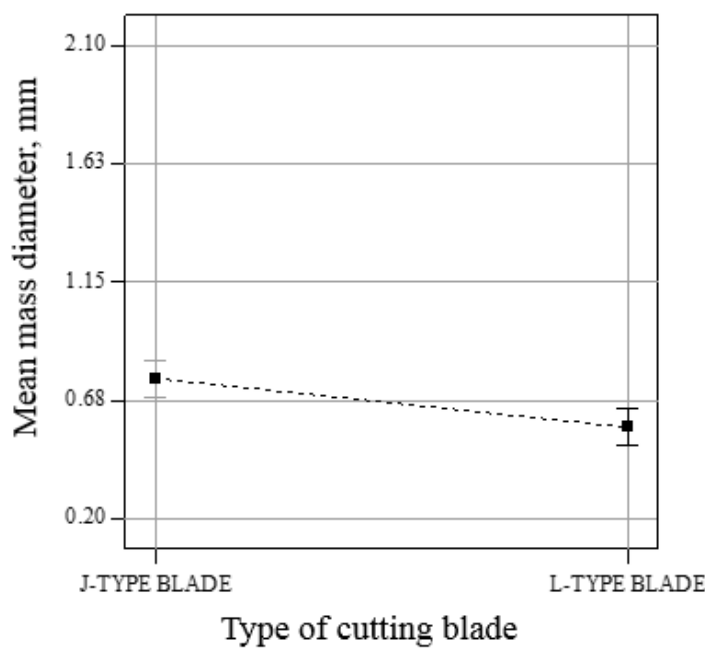

(a)

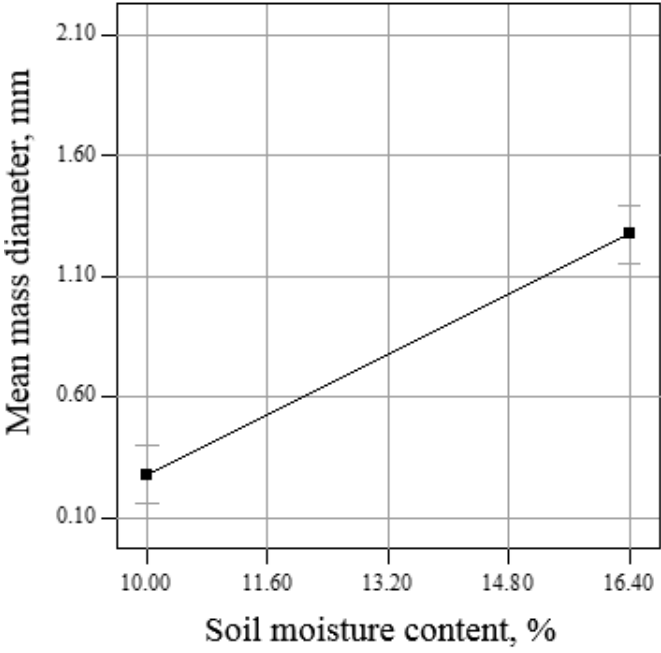

(b) 


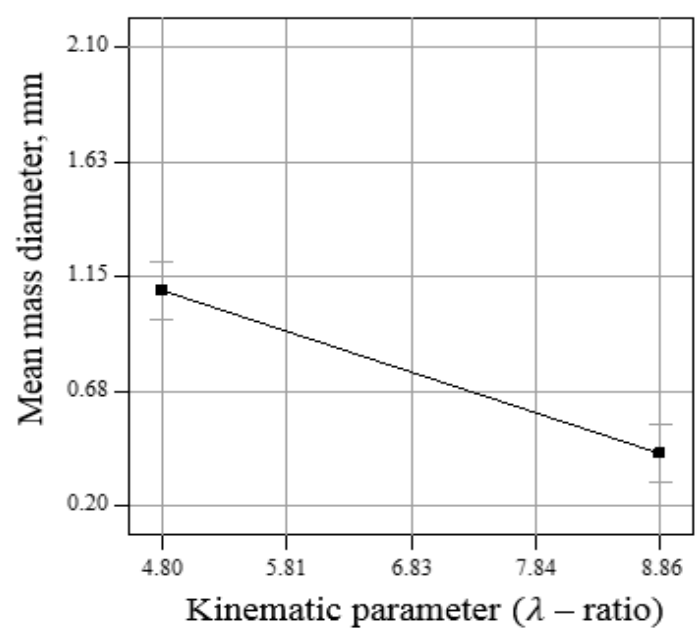

(c)

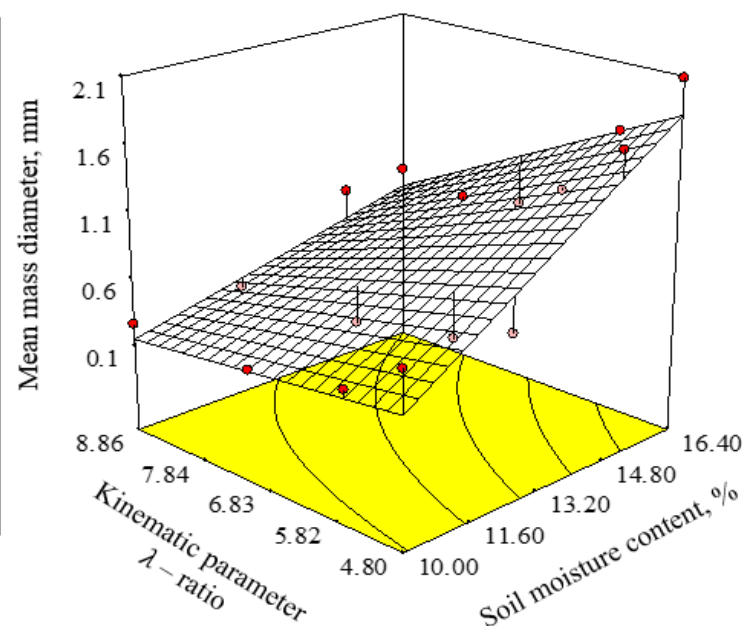

(d)

Fig.8 Representation of the individual effect of the cutting blade on (a), soil moisture content (b), the kinematic parameter (c), and interaction effect (d) fuel consumption

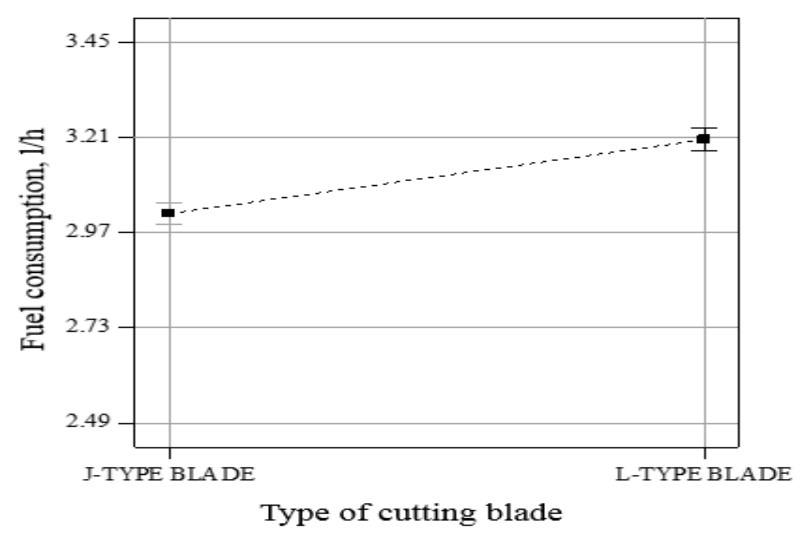

(a)

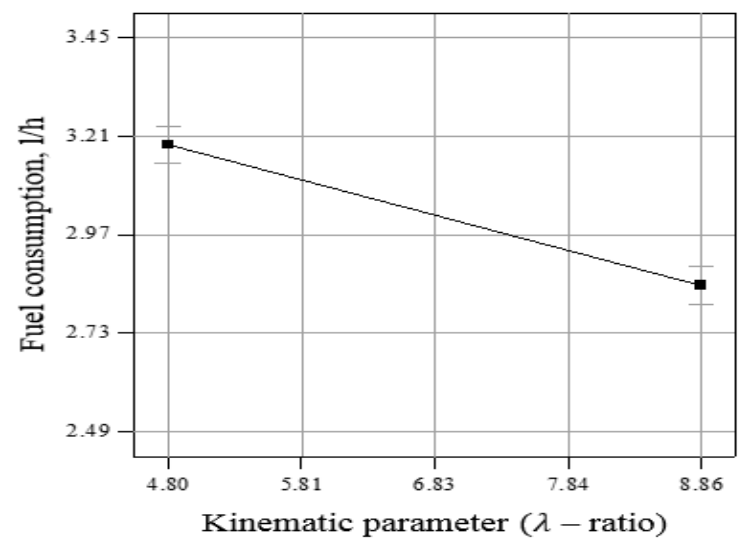

(c)

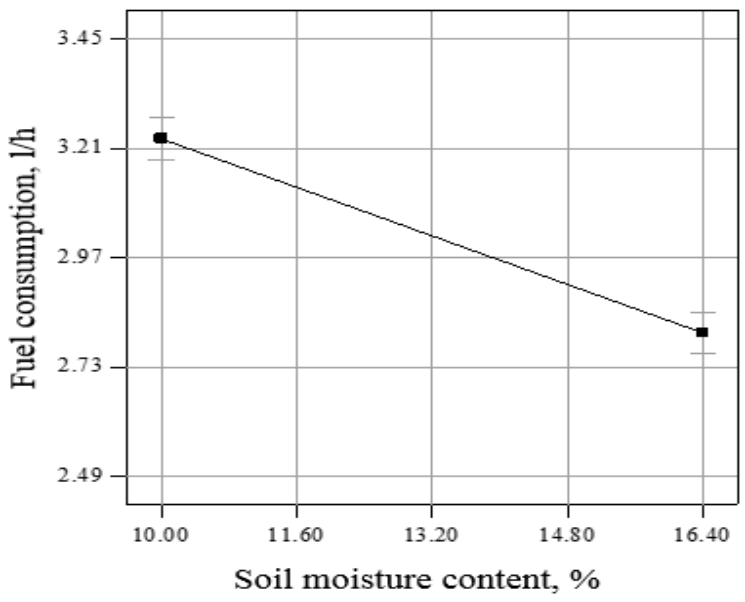

(b)

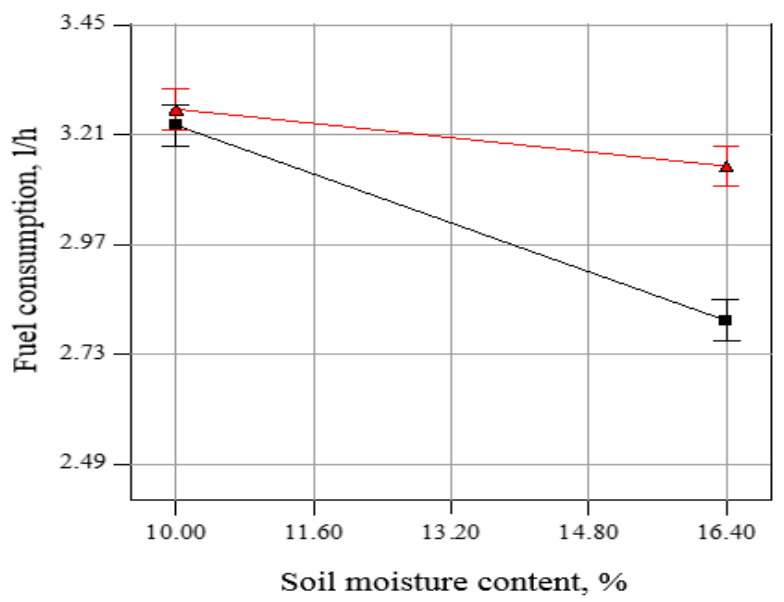

(d) 
Fig.9 (a) Desirability ramp for optimization of blade J (b) Desirability ramp for optimization of blade $\mathrm{L}$

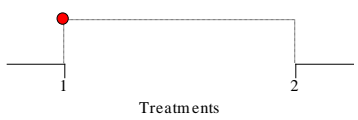

Treatments

Blade ty $\mathrm{pe}=1$

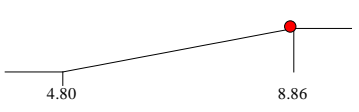

Lem bda ratio $=8.83$

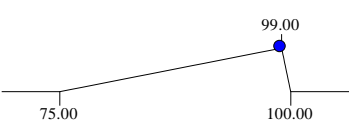

Weeding efficiency, $\%=99.00$

Desirability $=0.917$
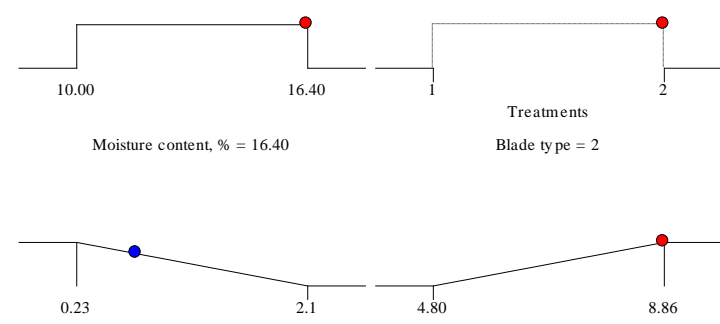

Mean mass diameter, $\mathrm{mm}=0.7$

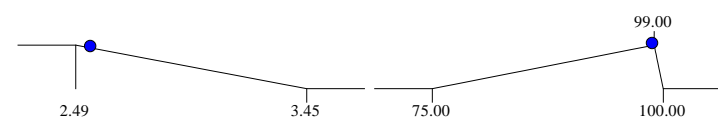

Fuel cunsum ption, $1 / \mathrm{h}=2.56$
Weeding efficiency, $\%=99.00$
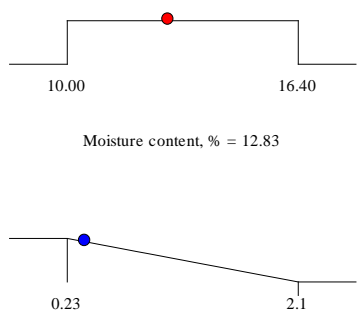

Mean mass diameter, $\mathrm{mm}=0.38$

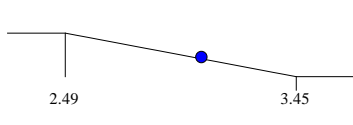

Fuel cunsumption, $1 / \mathrm{h}=3.06$

(a)

(b)

Fig.10 Graph showing the desirability of optimized parameters for J-shape blade

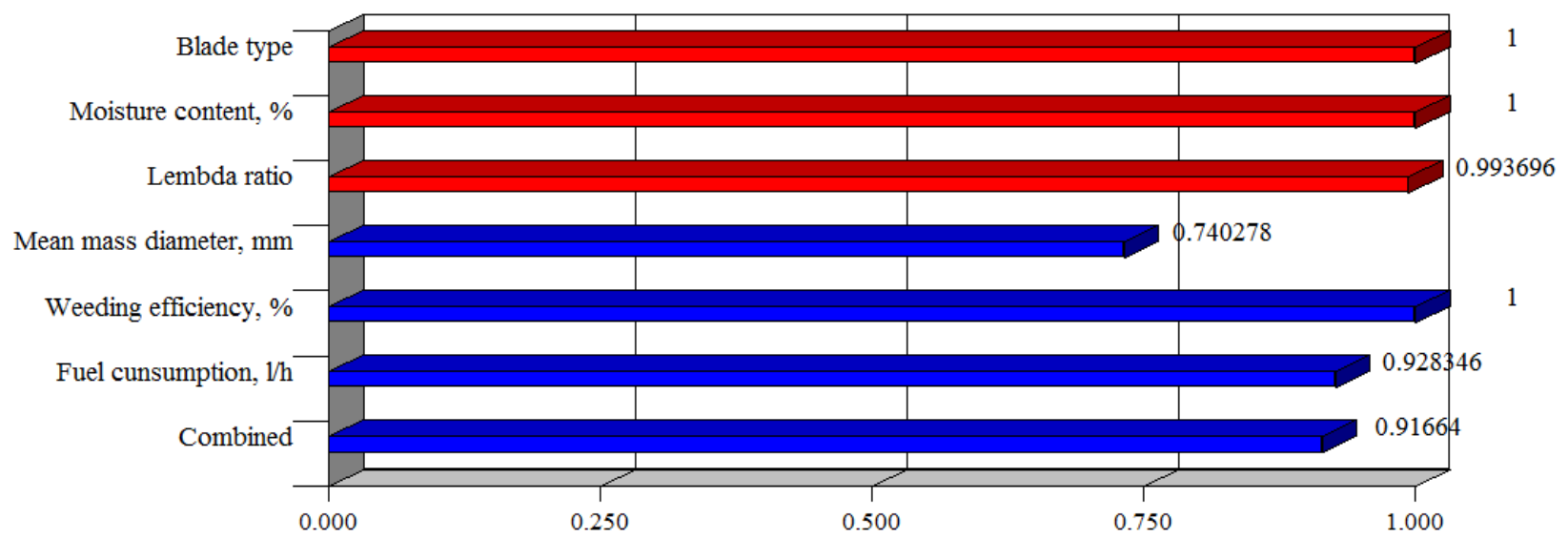

Fig.11 Graph showing the desirability of optimized parameters for L-shape blade

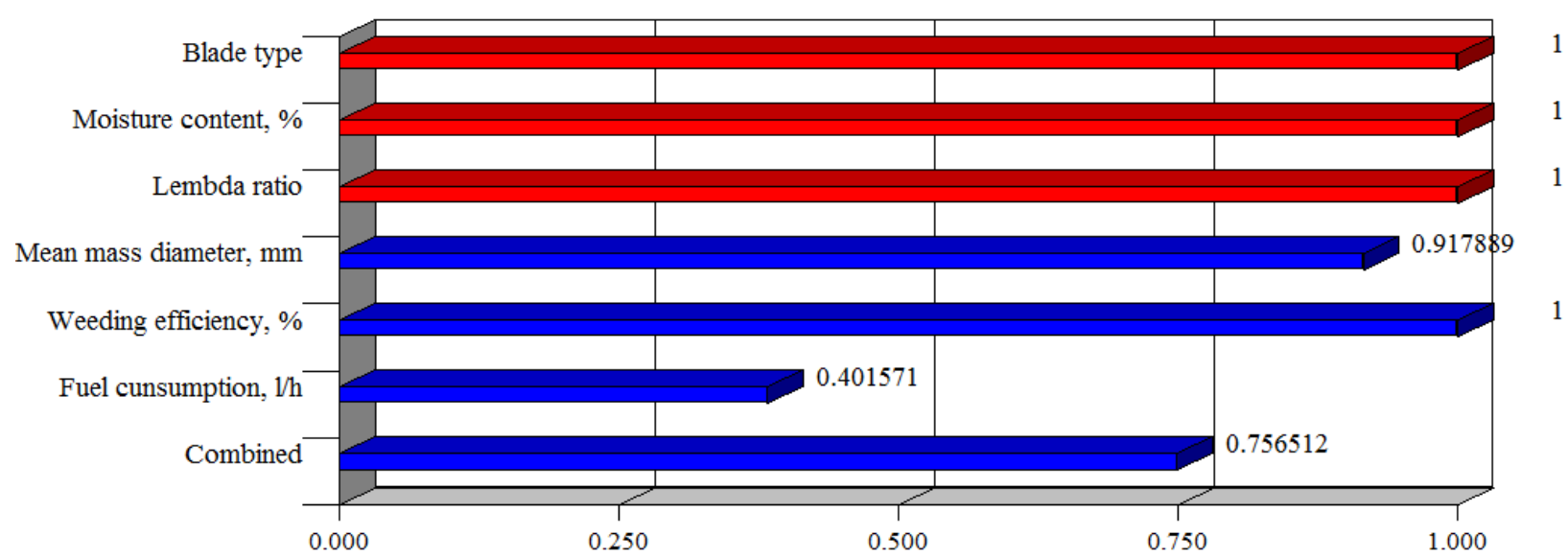


The input values given to model during the optimization process are given in Table 6 . The upper and lower limit of the variables was put and their criteria have been selected whether the responses have to be maximized, minimized or have an allotted limit. The allotted limits are within the values as accepted in the experiment. The whole criteria finalized by setting the goal and their importance (grading out of 5) on the basis of the importance of the response. It was found that the soil MMD, weeding efficiency and fuel consumption was $0.38 \mathrm{~mm}, 99 \%$ and $3.06 \mathrm{l} / \mathrm{h}$ respectively. It is the best outcomes obtained by L-type blade at $12.83 \%$ soil moisture and 8.86 lambda ratio.

The ramp optimization graphs are shown in Figure 9(a) and 9(b) for J and L-type soil cutting blades respectively. It shows the optimized value of soil particle size, weeding efficiency and fuel consumption for the side shift offset rotavator. The red and blue dots on the ramp indicates the dependent and independent parameters respectively. Whereas, the direction of the slope from left to right, from right to left and straightramp, indicates that the parameter is targeted to minimize, maximize and in range respectively.

The bar graph shown in Figure 10 and 11 represents the desirability of the blade type, moisture content, lambda ratio at optimized soil mean mass dia., weeding efficiency and fuel consumption. For each variable, it varies from 0 to 1 . The value near to 1 indicates that the response is more close to its targeted value.

The reduced models were obtained by eliminating the non-significant term from the model. The reduced model and their statistical data obtained from the ANOVA are given in Table 7. The value of the coefficient of determination was greater than 0.8 shows the model was a good fit for the third order polynomial equation. These models were significant at $1 \%$ level of significance. All the reduced response model were adequate because the value of adequate precision was greater than 4 for both type of blades Beg et al, (2003).

The important conclusions which were drawn from the experiments that the pulverization of the soil through L-shape blade was $86.84 \%$ better than the $\mathrm{J}$-shape blade at optimized soil moisture content of $16.40 \%$ and the lambda ratio of 8.83 . Thus, it can be concluded that the soil treated with L-shape soil cutting blade develops more uniformity and fineness for the soil bed as compared to J-shape blade. Although, the fuel consumption was found to be $19.53 \%$ higher for the optimized values of the soil moisture and lambda ratio in L-shape blade. The interesting point which was pointed out in case of L-shapeblade is that it develops no untilled soil as structures in $\mathrm{J}$ shape blade. These results confirm that the Lshape blades are the efficient substitute of $\mathrm{J}$ shape blade in perspective of quality of operation.

\section{References}

Beg, Q.K., Sahai, V. and Gupta, R., 2003. Statistical media optimization and alkaline protease production from Bacillus mojavensis in a bioreactor. Process Biochemistry, 39(2), pp.203209.

Destain, M.F. and Houmy, K., 1990. Effects of design and kinematic parameters of rotary cultivators on soil structure. Soil and Tillage Research, 17(3-4), pp.291301.

Gill, W.R. and Hendrick, J.G., 1976. The irregularity of soil disturbance depth by circular and rotating tillage tools. TRANSACTIONS of the ASAE, 19(2), pp.230-0233. 
Hendrick, J.G. and W.R. Gill. 1971a. Rotary tiller design parameters: I-Direction of rotation. 44 Transaction of the ASAE 14(4): 669-674, 683.

Hendrick, J.G. and W.R. Gill. 197lc. Rotary tiller design parameters: III-Ratio of peripheral and forward velocities. Transaction of the ASAE 14(4): 679683.

Marenya, M.O., 2010. Performance characteristics of a deep tilling rotavator (Doctoral dissertation).

\section{How to cite this article:}

Shekhar Kumar Sahu, Kunj Bihari Tiwari, Prateek Shrivastava and Rohit Namdeo. 2018. Optimization of the Kinematic Parameter and Fuel Consumption for the Side-Shift Offset Rotavator Using L and J-Shape Soil Cutting Blades. Int.J.Curr.Microbiol.App.Sci. 7(08): 1970-1982. doi: https://doi.org/10.20546/ijcmas.2018.708.227 